\title{
Muscle-Derived Collagen XIII Regulates Maturation of the Skeletal Neuromuscular Junction
}

\author{
Anne Latvanlehto, ${ }^{1,2,3}$ Michael A. Fox, ${ }^{6,7}$ Raija Sormunen, ${ }^{2,4}$ Hongmin Tu, ${ }^{1,2,3}$ Tuomo Oikarainen, ${ }^{1,2,3}$ Anu Koski, ${ }^{1,2,3}$ \\ Nikolay Naumenko, ${ }^{8}$ Anastasia Shakirzyanova, ${ }^{8,9}$ Mika Kallio, ${ }^{10}$ Mika Ilves, ${ }^{2,5,11}$ Rashid Giniatullin, ${ }^{8}$ Joshua R. Sanes, ${ }^{6}$ \\ and Taina Pihlajaniemi ${ }^{1,2,3}$ \\ ${ }^{1}$ Oulu Center for Cell-Matrix Research, ${ }^{2}$ Biocenter Oulu, and Departments of ${ }^{3}$ Medical Biochemistry and Molecular Biology, ${ }^{4}$ Pathology, and ${ }^{5} \mathrm{Physiology}$, \\ 90014 University of Oulu, Finland, ${ }^{6}$ Department of Molecular and Cellular Biology and Center for Brain Science, Harvard University, Cambridge, \\ Massachusetts 02138, ${ }^{7}$ Department of Anatomy and Neurobiology, Virginia Commonwealth University Medical Center, Richmond, Virginia $23298,{ }^{8}$ A. I. \\ Virtanen Institute for Molecular Sciences, Department of Neurobiology, University of Eastern Finland, 70600 Kuopio, Finland, ${ }^{9}$ Kazan Institute of \\ Biochemistry and Biophysics Kazan Science Centre, Russian Academy of Science, 420111 Kazan, Russia, ${ }^{10}$ Department of Clinical Neurophysiology, Oulu \\ University Hospital, 90221 Oulu, Finland, and ${ }^{11}$ Department of Basic Veterinary Sciences, Division of Anatomy, 00014 University of Helsinki, Finland
}

Formation, maturation, stabilization, and functional efficacy of the neuromuscular junction (NMJ) are orchestrated by transsynaptic and autocrine signals embedded within the synaptic cleft. Here, we demonstrate that collagen XIII, a nonfibrillar transmembrane collagen, is another such signal. We show that collagen XIII is expressed by muscle and its ectodomain can be proteolytically shed into the extracellular matrix. The collagen XIII protein was found present in the postsynaptic membrane and synaptic basement membrane. To identify a role for collagen XIII at the NMJ, mice were generated lacking this collagen. Morphological and ultrastructural analysis of the NMJ revealed incomplete adhesion of presynaptic and postsynaptic specializations in collagen XIII-deficient mice of both genders. Strikingly, Schwann cells erroneously enwrapped nerve terminals and invaginated into the synaptic cleft, resulting in a decreased contact surface for neurotransmission. Consistent with morphological findings, electrophysiological studies indicated both postsynaptic and presynaptic defects in Col13a1 ${ }^{-/-}$mice, such as decreased amplitude of postsynaptic potentials, diminished probabilities of spontaneous release and reduced readily releasable neurotransmitter pool. To identify the role of collagen XIII at the NMJ, shed ectodomain of collagen XIII was applied to cultured myotubes, and it was found to advance acetylcholine receptor (AChR) cluster maturation. Together with the delay in AChR cluster development observed in collagen XIII-deficient mutants in vivo, these results suggest that collagen XIII plays an autocrine role in postsynaptic maturation of the NMJ. Altogether, the results presented here reveal that collagen XIII is a novel muscle-derived cue necessary for the maturation and function of the vertebrate NMJ.

\section{Introduction}

Development of the neuromuscular junction (NMJ) is controlled by a repertoire of autocrine and transsynaptic signals (Fox and Umemori, 2006; Kummer et al., 2006; Fox, 2008). This includes secreted molecules that are stably associated with the synaptic basement membrane (BM) (Sanes, 2003). Motor nerves, for example, secrete an alternatively spliced form of the heparan sulfate

\footnotetext{
Received Nov. 9, 2009; revised May 5, 2010; accepted May 13, 2010.

This work was supported by Academy of Finland Research Council for Health Grants 115237 (T.P.) and 127674 (A.L.), Academy of Finland Research Council for Biosciences and Environment Grant 127150 (R.G.), the Sigrid Jusélius Foundation, the Biocenter Oulu Graduate School, and grants from the National Institutes of Health (J.R.S.). N.N. and A.S. were supported by Centre for International Mobility grants. The Zebrafish International Resource Center providing the synaptotagmin 2 antibody was supported by National Institutes of Health/National Center for Research Resources Grant P40 RR012546. We thank Dr. Jun-ichi Miyazaki (Osaka University, Osaka, Japan) for providing the CAG-Cre transgenic mice, Dr. Raija Soininen for providing the LacZ-neo ${ }^{r}$ cassette, Prof. Uolevi Tolonen for providing expertise on electroneuromyography, Sirkka Vilmi, Aila White, Tuula Taskinen, Sirpa Kellokumpu, Tarja Piispanen, and Anna-Liisa Oikarainen for technical assistance, and Eija Nissinen, Tanja Sankala, Annemari Lyytinen, Sanna Haapalainen, Miia Virkkunen, and Tapio Rautio for taking care of the animals.

Correspondence should be addressed to Taina Pihlajaniemi, Oulu Center for Cell-Matrix Research, Biocenter Oulu, Department of Medical Biochemistry and Molecular Biology, University of Oulu, P.0. Box 5000,90014 Oulu, Finland. E-mail: taina.pihlajaniemi@oulu.fi.

DOI:10.1523/JNEUROSCI.5518-09.2010

Copyright $\odot 2010$ the authors $\quad 0270-6474 / 10 / 3012230-12 \$ 15.00 / 0$
}

proteoglycan agrin, which organizes and stabilizes components of the postsynaptic membrane (Gautam et al., 1996). Conversely, muscle-derived $\beta 2$-containing laminins bind to receptors on nerve terminals, organizing and stabilizing neurotransmitter release sites (Noakes et al., 1995; Patton et al., 2001; Nishimune et al., 2004). Synaptic laminins can also promote postsynaptic maturation by a direct autocrine effect on receptors, such as dystroglycan in the postsynaptic membrane (Nishimune et al., 2008).

Collagens comprise another prominent set of extracellular matrix (ECM) components of importance for NMJ development and function (Fox, 2008). A short collagen, ColQ, is required to anchor the neurotransmitter-inactivating enzyme acetylcholinesterase to synapses (Feng et al., 1999; Rotundo, 2003). Although well studied for their roles as structural and anchoring molecules, it is now apparent that some collagens and/or proteolytically shed fragments of collagens can themselves act as extracellular signaling molecules (Ortega and Werb, 2002). In this regard, type IV collagens, the major structural components of the synaptic BM, have been identified recently as transsynaptic organizers via their cleaved non-collagenous (NC) domains. Moreover, genetic deletion of the synapse-specific $\alpha 3-6$ (IV) chains 
demonstrated their role in the maturation and maintenance of the NMJ (Fox et al., 2007).

Here we demonstrate the synaptic localization and role of another collagen, collagen XIII, a homotrimeric transmembrane protein with three collagenous domains (COL1-COL3) interrupted and flanked by NC sequences (Hägg et al., 1998; Snellman et al., 2000b) (see Fig. 2A). In addition to being an integral transmembrane protein, collagen XIII can be shed by proprotein convertases (Snellman et al., 2000a), and the shed ectodomain affects the migration and proliferation of cultured cells (Väisänen et al., 2004). Collagen XIII is expressed in almost all tissues studied but at relatively low levels in most of them (Hägg et al., 2001; Sund et al., 2001a). Previous analyses of mice that overexpress normal or truncated collagen XIII have revealed defects in several tissues. Mice harboring a secreted ectodomain but lacking the membrane-anchored collagen XIII develop progressive myopathy with abnormalities in the BM of myotendinous junction (MTJ) (Kvist et al., 2001). Mice overexpressing truncated collagen XIII develop lethal phenotype attributable to defective cell adhesions and angiogenesis in the heart and placenta (Sund et al., 2001b; Tahkola et al., 2008). Conversely, overexpression of the normal collagen XIII protein leads to massive overgrowth of bones (Ylönen et al., 2005). However, loss-of-function analysis to show the role of endogenous collagen XIII has yet to be reported. Using immunohistochemistry, cellular protein fractionation, and a novel gene-targeted reporter mouse line (Col13a $\left.{ }^{\mathrm{LacZ}}\right)$, we now show that collagen XIII is expressed by muscle fibers and concentrated on the postsynaptic membrane, from where it can be shed into the synaptic cleft. Importantly, results obtained with the collagen XIII null mice (Col13a1 ${ }^{-/-}$) generated here revealed that collagen XIII is a third collagenous molecule required for the normal organization and function of the vertebrate NMJ.

\section{Materials and Methods}

Generation of mouse lines. All the animal experiments followed the laws and regulations on the care and use of laboratory animals. Permission was obtained from the Animal Care and Use Committee of the University of Oulu for the generation and maintenance of all the mouse models presented here.

To generate the $\beta$-galactosidase reporter mouse line, the $1.2 \mathrm{~kb}$ NarI fragment, including most of the exon 2 coding sequences and the beginning of the second intron in the $7.4 \mathrm{~kb}$ BamHI genomic clone, was replaced by the $L a c Z / n e o^{\mathrm{r}}$ cassette. The reporter was fused in-frame with the exon 2 sequences because this exon is present in all collagen XIII transcript variants (Peltonen et al., 1997; Kvist et al., 1999). By insertion of the LacZ gene with its own translation stop codon into the second exon in-frame with collagen XIII sequences, the furin endoprotease recognition sequence was destroyed, which made it impossible to release $\beta$-galactosidase from the cell membrane (see Fig. $2 A$ ). The Col13a1 LacZ allele was generated in the Transgenic Core Facility of Biocenter Oulu according to standard methods. Chimeric mice were bred with C57BL/6 mice to generate inbred Col13a1 ${ }^{\text {LacZ }}$ lines (supplemental Fig. S1, available at www.jneurosci.org as supplemental material).

Generation of the knock-out vector was initiated by inserting a neo ${ }^{\mathrm{r}}$ cassette flanked by loxP sequences in reverse orientation in the $9 \mathrm{~kb}$ genomic BamHI fragment to replace the $2.3 \mathrm{~kb}$ sequence, including the predicted promoter area, $5^{\prime}$ untranslated region (UTR) sequences, and the first protein-coding exon. The Coll3 $a 1^{\mathrm{T}}$ allele was generated using methods described previously (Nagy et al., 1993; Fässler and Meyer, 1995), and the Col13a1 ${ }^{-}$allele was obtained by mating the Col13a1 ${ }^{\mathrm{T} / \mathrm{T}}$ male mice with Cre-expressing females, which retain Cre recombinase activity in mature oocytes regardless of Cre transgene transmission (Sakai and Miyazaki, 1997). The resultant mice were bred with C57BL/6 mice to establish an inbred Col13 $a^{-}$line (supplemental Fig. S3, available at www.jneurosci.org as supplemental material).
Tissue transcript and protein level analyses. Total RNA was extracted from wild-type and Col13a1 ${ }^{-}$embryonic day 16 (E16) fetuses and tissue samples from adult mice using a Tri Reagent system (Sigma-Aldrich) and used for quantitative real-time PCR with the ABI 7700 Sequence detection system as described previously (Sund et al., 2001a). The TaqMan oligonucleotide primers for mouse collagen XIII were $5^{\prime}$-GGGAAGCCCCGAAGTGT-3' and $5^{\prime}$-TCTTCCAGTGGGACC-3' with the fluorogenic probe $5^{\prime}$-FamTCCAGGATGTAA CTGCCCACCAGGA-Tamra-3' [nucleotides 789806 , complementary to nucleotides $834-853$ and nucleotides $808-832$ in GenBank accession number NM_007731 (Hägg et al., 1998), respectively] in the area of exons 2-4 and 5'-GCAAAGGAGAGATGGTGGATTATAA-3' and $5^{\prime}$-CAAGGCCAGCGTCCTGAT-3' with the probe 5'-Fam-CAGCATCAACGAGG CGCTTCAG-Tamra-3' [nucleotides 1800-1824, complementary to nucleotides 1853-1870 and nucleotides 1828-1849 in GenBank accession number NM_007731 (Hägg et al., 1998), respectively] in the area of exons 26-27, which participates in coding of the NC3 domain.

Protein was extracted from wild-type and Col13a1 ${ }^{-}$tissues using the Tri Reagent system. Twenty micrograms of tissue protein were run on an $8 \%$ reduced SDS-PAGE and Western blotted with a rabbit anti-human collagen XIII/NC3 antibody (Hägg et al., 1998).

Histology. Pieces of mouse tissue were stained using $\beta$-galactosidase enzyme activity as described previously (Gossler and Zachgo, 1993). In brief, tissues were fixed shortly in $0.2 \%$ glutaraldehyde, 5 mM EGTA, 2 $\mathrm{mM} \mathrm{MgCl}_{2}$, and $0.1 \mathrm{M}$ potassium phosphate buffer, $\mathrm{pH} 7.3$, and washed in wash solution (0.01\% sodium deoxycholate, $0.02 \%$ NP-40, 5 mM EGTA, $2 \mathrm{mM} \mathrm{MgCl}_{2}$, and $0.1 \mathrm{M}$ phosphate buffer, $\mathrm{pH}$ 7.3). Samples protected from light were stained for $24 \mathrm{~h}$ at room temperature (RT) in $10 \mathrm{~mm}$ $\mathrm{K}_{3} \mathrm{Fe}(\mathrm{CN})_{6}, \mathrm{~K}_{4} \mathrm{Fe}(\mathrm{CN})_{6}$, and $1 \mathrm{mg} / \mathrm{ml}$ 5-bromo-4-chloro-3-indolyl- $\beta$-Dgalactopyranoside (X-gal) in wash solution and washed as above. Postfixing of tissues was performed with phosphate-buffered Formalin for $24 \mathrm{~h}$, and, after washing, the samples were viewed under an Olympus SZ61 microscope. Tissue samples were embedded in paraffin, and sections of $10 \mu \mathrm{m}$ were stained with eosin and viewed on an Olympus BX51 microscope.

The NMJ-rich regions of diaphragm muscles from postnatal day 28 (P28) wild-type mice and of quadriceps muscles from P56 wild-type mice for immunoelectron microscopy were fixed for $2 \mathrm{~h}$ at room temperature in $4 \%$ paraformaldehyde (PFA) and $2.5 \%$ sucrose in $0.1 \mathrm{~m}$ phosphate buffer, $\mathrm{pH}$ 7.4, immersed for $24 \mathrm{~h}$ in $2.3 \mathrm{~m}$ sucrose, and frozen. Thin frozen sections were blocked in 5\% BSA and $0.1 \%$ cold water fish skin gelatin (Aurion) in PBS and stained with a rabbit anti-mouse collagen XIII/NC3 antibody (Kvist et al., 2001) or with the anti-human collagen XIII/NC3 antibody in 0.1\% BSA-C (Aurion) in PBS for $1 \mathrm{~h}$. The mouse and human NC3 domains are 22 residues in length, they differ by a single residue (Hägg et al., 1998), and both antibodies produce the same staining patterns. Sections were washed with $0.1 \%$ BSA-C and incubated with protein A-gold complex (size, $10 \mathrm{~nm}$ ) in $0.1 \%$ BSA-C for $30 \mathrm{~min}$, followed by washing. The controls were prepared by performing the labeling procedure without primary antibodies. The sections were embedded in methylcellulose and examined in a Philips CM100 transmission electron microscope (Philips Export B.V.) at an acceleration voltage of $80 \mathrm{kV}$. Image acquisition was performed using a CCD camera and Electron Microscopy Menu version 2.1 from Tietz Video and Image Processing Systems.

For electron microscopy, the NMJ-rich regions of quadriceps muscles from P28 and diaphragm muscles from P56 wild-type and Col13a1 ${ }^{-/-}$ mice or quadriceps muscles from P28 Col13a1 LacZ/LacZ and P112 Col13a $1^{\mathrm{LacZ} /+}$ mice prestained for $\beta$-galactosidase enzyme activity were fixed in $1 \%$ glutaraldehyde and $4 \%$ PFA in $0.1 \mathrm{~m}$ phosphate buffer, $\mathrm{pH}$ 7.3 , postfixed in $1 \%$ osmium tetroxide, dehydrated in acetone, and embedded in Epon LX112. Semithin sections were stained with toluidine blue and analyzed on an Olympus BX51 microscope. Thin sections were analyzed using a Philips CM100 transmission electron microscope, and images were captured by a Morada CCD camera (Olympus Soft Imaging Solutions).

For whole-mount staining, muscles from wild-type and Col13a1 ${ }^{-1-}$ mice were fixed for $24 \mathrm{~h}$ in $4 \%$ PFA, washed in PBS, incubated in blocking buffer $(2.5 \%$ BSA, $2.5 \%$ normal goat serum, and $0.2 \%$ Triton X-100 in PBS) for $24 \mathrm{~h}$, and incubated in the primary antibodies diluted in blocking 
buffer for $48 \mathrm{~h}$. After a $24 \mathrm{~h}$ washing, the muscles were incubated with fluorescently labeled secondary antibodies supplemented with $\alpha$-bungarotoxin (BTX) in blocking buffer for $24 \mathrm{~h}$, followed by washing and mounting. All the incubations took place at $4^{\circ} \mathrm{C}$. The samples were imaged on an Olympus FV1000 scanning confocal microscope.

Five to $15 \mu \mathrm{m}$ frozen tissue sections were stained unfixed (antiEscherichia coli $\beta$-galactosidase together with anti-neurofilament) or fixed in ice-cold acetone for $10 \mathrm{~min}$ (anti-human/mouse collagen XIII/ NC3), washed in PBS, and incubated in blocking buffer (5\% nonfat milk or 5\% normal goat serum) for 30-60 min, with the primary antibodies overnight at $4^{\circ} \mathrm{C}$ and with the secondary antibodies for $1 \mathrm{~h}$ at RT. After washing, the sections were mounted and visualized with an Olympus FV1000 scanning confocal microscope.

The antibodies used for the stainings were anti-E. coli $\beta$-galactosidase (Rockland), anti-human collagen XIII/NC3 (Hägg et al., 1998), antimouse collagen XIII/NC3 (Kvist et al., 2001), anti-neurofilament (SMI 312; Covance Research Products), and anti-synaptotagmin 2 (Syt2) (Zebrafish International Resource Center). Tetramethylrhodamine and Alexa 488-conjugated BTX and secondary antibodies were obtained from Invitrogen.

Cell cultures. C2C12 cells were obtained from American Type Culture Collection and maintained in DMEM (Invitrogen) with 20\% fetal calf serum. Acetylcholine receptor (AChR) clustering was induced by plating C2C12 myoblasts on laminin-coated dishes (EHS laminin; Invitrogen) as described previously (Kummer et al., 2004). To induce differentiation, the medium was changed to DMEM with $2 \%$ horse serum supplemented with $10 \mu \mathrm{M}$ tetrodotoxin (TTX) (Sankyo) to prevent muscle contraction. Optionally, $1-5 \mu \mathrm{g} / \mathrm{ml}$ recombinant human collagen XIII ectodomain (Tu et al., 2002) or recombinant NC1 domain of collagen IV (5 $\mu \mathrm{g} / \mathrm{ml})$, known not to have any effect on AChR clustering (Fox et al., 2007), were added to the fusion medium. Cultures on $75 \mathrm{~cm}^{2}$ plates were used for Western blotting, and cells on eight-well chamber slides (Nalge Nunc International) were used for immunofluorescent stainings.

Proteins in C2C12 myotubes differentiated for $4 \mathrm{~d}$ were fractionated as described previously (Hägg et al., 1998) and subjected to Western blotting together with the whole-cell lysates from $\mathrm{C} 2 \mathrm{C} 12$ myoblasts and myotubes and conditioned medium from myotubes with the anti-human collagen XIII/NC3 antibody. Briefly, cells were detached in HES buffer (0.25 $\mathrm{m}$ sucrose, $1 \mathrm{~mm}$ EGTA, and $5 \mathrm{~mm}$ HEPES, pH 7.4) with a scraper and washed by pelleting with $1900 \times g$ for $10 \mathrm{~min}$. The pellet was resuspended with 3 v/w HES and homogenized with a Potter-Elvehjem homogenizer at $1500 \mathrm{rpm} 60$ times. Nuclei were pelleted by centrifuging with $578 \times g$ for $10 \mathrm{~min}$, and membranes were recovered from the supernatant by centrifuging with $37,000 \times g$ for $60 \mathrm{~min}$. Proteins associated noncovalently with membranes were released by suspending the membrane pellet with $1 \mathrm{~m} \mathrm{NaCl}$. Membranes were further recovered from the supernatant, now containing the membrane-associated proteins, by centrifuging with $37,000 \times g$ for $40 \mathrm{~min}$. The membranes were solubilized with $0.15 \mathrm{M} \mathrm{NaCl}, 1 \%$ Nonidet P-40, and $10 \mathrm{~mm}$ HEPES, pH 7.4, overnight in rotation to solubilize transmembrane proteins. All solutions contained the EDTA-free complete proteinase inhibitor (Roche), and all steps were at $+4^{\circ} \mathrm{C}$. To equal the sample volumes, proteins were precipitated with 3 vol of methanol before Western blotting.

For stainings, the cultured cells were fixed for $30 \mathrm{~min}$ at RT with $4 \%$ PFA and $4 \%$ sucrose, washed in PBS, and incubated in blocking buffer (2.5\% BSA, $2.5 \%$ normal goat serum, and $0.2 \%$ Triton X-100 in PBS) for $2 \mathrm{~h}$ and then with the primary antibodies anti-LL5 $\beta$ (Kishi et al., 2005) and/or with BTX in blocking buffer for $24 \mathrm{~h}$ at $4^{\circ} \mathrm{C}$. After washing, the cells were incubated with fluorescently labeled secondary antibodies for $1 \mathrm{~h}$ at RT, washed, mounted, and imaged on an Olympus FV1000 scanning confocal microscope.

Electrophysiology. Resting membrane potential, postsynaptic endplate potential (EPP), and miniature end-plate potential (MEPP) experiments were determined at room temperature on 3-month-old wild-type and Col13a1 ${ }^{-/-}$mice diaphragm muscles in vitro. Animals, in accordance with the European Communities Council Directive (November 24, 1986; 86/609/EEC), before dissection were anesthetized with slowly raised $\mathrm{CO}_{2}$ and then quickly decapitated. Diaphragm muscles were immediately dissected and put into the organic glass chamber $(3 \mathrm{ml})$ with the bottom covered with Sylgard (World Precision Instruments). To prevent muscle contractions and preserve physiologically high level of transmitter release in experiments with stimulation of motor nerve, muscle fibers were cut transversely (Giniatullin et al., 1993), followed by rinsing with Krebs' solution for at least $30 \mathrm{~min}$ before recording. Recording of MEPPs was performed on uncut muscles. All solutions were applied to the muscle via the superfusion system at the rate of $2 \mathrm{ml} / \mathrm{min}$. Physiological Krebs' solution contained $120 \mathrm{~mm} \mathrm{NaCl}, 5 \mathrm{~mm} \mathrm{KCl}, 2 \mathrm{~mm}$ $\mathrm{CaCl}_{2}, 1 \mathrm{~mm} \mathrm{MgCl}_{2}, 11 \mathrm{~mm}$ glucose, $1 \mathrm{~mm} \mathrm{NaHPO}_{4}$, and $24 \mathrm{~mm} \mathrm{NaHCO}_{3}$ (gassed with $95 \% \mathrm{O}_{2}, 5 \% \mathrm{CO}_{2}$ ). $\mathrm{pH}$ of all solutions was adjusted to 7.4. In some experiments, solutions supplemented with $500 \mathrm{~mm}$ sucrose and up to $15 \mathrm{~mm} \mathrm{KCl}$ (accompanied by the proportional $\mathrm{NaCl}$ reduction) were used. The excessive activity and generation of spontaneous action potentials was prevented with $1 \mu \mathrm{M}$ TTX (Ascent Scientific).

All recordings were performed using the standard single microelectrode technique. Electrodes filled with $3 \mathrm{M} \mathrm{KCl}$ had resistance in the range of $10-15 \mathrm{M} \Omega$. Only synapses with membrane potential fall $<5 \mathrm{mV}$ during the observation period were taken into consideration. Paired EPPs (at least six pairs with $30 \mathrm{~ms}$ between the stimuli) were elicited by supramaximal nerve stimulation using the stimulus generator A365 (World Precision Instruments). MEPPs were continuously recorded for $2 \mathrm{~min}$ from individual muscle fibers. Synaptic signals (EPPs and MEPPs) digitized at $100 \mathrm{kHz}$ were recorded using a low-noise custom-made amplifier were acquired to the personal computer through the data acquisition board NI PCI6221 (National Instruments) and WinEDR version 3.0.4 software (Strathclyde University, Glascow, Scotland, UK). Offline analysis of signal amplitudes, rise times, decay times, and interevent intervals of MEPPs was performed with ClampFit version 10.2.0.14 (Molecular Devices). Final analysis was made using Origin software, version 8.0 (OriginLab Corp.).

Electroneuromyography. For the evaluation of peripheral nerve function and neuromuscular transmission, nerve conduction velocity (NCV) and repetitive stimulation studies (Kimura, 2001) were performed using recording techniques adapted and modified from what has been described previously (Stanley, 1981). Both motor nerve conduction velocity $(\mathrm{MCV})$ and sensory nerve conduction velocity were determined. Additionally, $F$ latencies were measured, and repetitive stimulation studies were used.

For the recordings 3-month-old wild-type, Col13a1 ${ }^{\mathrm{N} / \mathrm{N}}$ (Kvist et al., 2001), Col13a1 ${ }^{\text {LacZ/LacZ }}$, and Col13a1 $1^{-1-}$ male mice were anesthetized with $30 / 2.5 \mathrm{mg} / \mathrm{kg}$ ketamine/xylazine to prevent discomfort. Body temperature was monitored with a dermal temperature probe and maintained at $32^{\circ} \mathrm{C}$ with a warming lamp during measurements. For the recording and stimulation, disposable $12 \mathrm{~mm}, 0.4$-mm-diameter platinum subdermal EEG electrodes (Nicolet Biomedical) were used. Surface electrodes were used for the repetitive stimulation studies. All NCV studies were performed with Keypoint Portable (Medtronic).

For the sciatic-tibial motor NCV studies, compound muscle potentials were recorded from the plantar flexor muscles. Recording electrode was inserted subcutaneously into the plantar muscles of the foot, and a reference electrode was placed distally into the footpad. A surface electrode wrapped around the tail served as a ground. Square pulses of fixed duration $(0.04 \mathrm{~ms})$ were used to stimulate the nerves. Supramaximal stimulation was given to obtain the maximum response. Latency was measured from initial onset to maximum negative peak. Amplitude was measured from peak to peak. The tibial nerve was stimulated at the sciatic notch and at the ankle. MCV was calculated by the conventional method: the distance divided by the difference between proximal and distal latencies. Flatency was determined with stimulation at the knee. Tail motor latency was determined by stimulating distally along the tail at a recorded distance of $3 \mathrm{~cm}$. Latency was measured from initial onset to maximum negative peak.

Tail sensory NCV was determined by stimulating proximally along the tail at a recorded distance of $3 \mathrm{~cm}$. Latency was measured from initial onset to maximum negative peak.

For the evaluation of neuromuscular transmission, repetitive stimulation studies were performed by stimulating the sciatic nerve at the sciatic notch and by recording compound muscle potentials from lateral gastrocnemius muscle. Surface recording electrodes were placed in the skin 
A

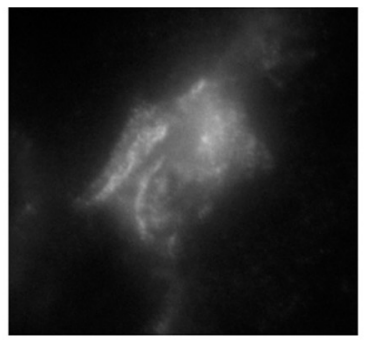

Col XIII

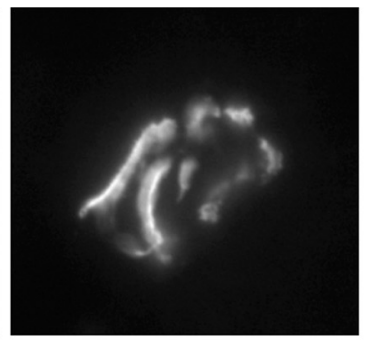

BTX

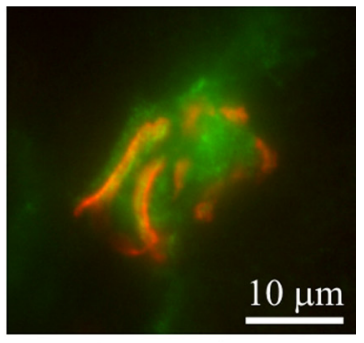

Col XIII / BTX
B

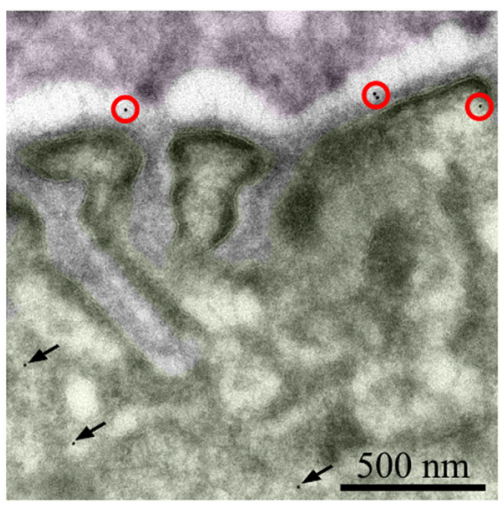

Col XIII

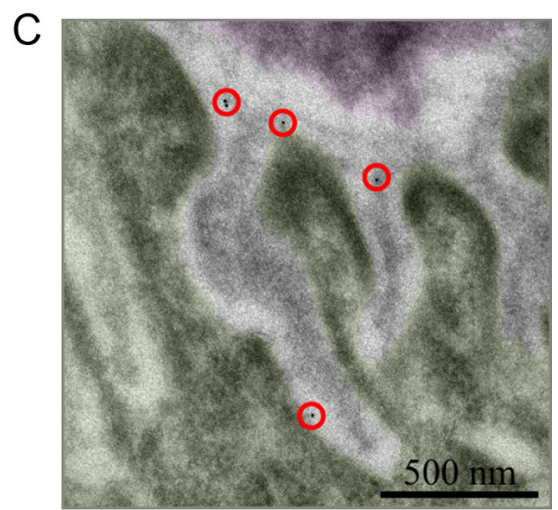

Col XIII

Figure 1. Collagen XIII is concentrated at the NMJ. $\boldsymbol{A}$, Wild-type mouse muscle sections are stained using an anti-human collagen XIII/NC3 antibody (CoIXIII; green) and BTX (red). B, C, Immunoelectron microscopy of P28 mouse diaphragm muscles with the anti-mouse collagen XIII/NC3 antibody ( $\boldsymbol{B})$ and of P56 quadriceps muscles with the anti-human collagen XIII/NC3 antibody (C). Muscle is indicated by transparent green and nerve terminal by transparent purple. Staining at the synaptic sarcolemma and in the adjacent $\mathrm{BM}$ is shown by red circles $(\boldsymbol{B}, \boldsymbol{C})$ and staining in the muscle beneath the NMJ by arrows $(\boldsymbol{B})$.

above the muscle and the reference in the footpad. The sciatic nerve was then stimulated at $3 \mathrm{~Hz}$. Maximum decrement was determined between the second and fifth compound muscle potential after stimulation.

Statistical analyses. The data are presented as the mean \pm SEM with statistical significance assessed by Student's paired $t$ test (for parametric data) or Mann-Whitney test (for nonparametric data). Statistically significant differences were indicated: ${ }^{\star} p<0.05$ and ${ }^{* *} p<0.001$.

\section{Results}

Collagen XIII is expressed by muscle and located at the NMJ To assess the presence of collagen XIII at the mouse NMJ, adult skeletal muscle was immunostained with an anti-human collagen XIII/NC3 antibody (Hägg et al., 1998) together with BTX, which selectively binds AChRs at the postsynaptic membrane. Collagen XIII appeared concentrated at and in close proximity to the NMJ (Fig. 1A). Synaptically localized collagen XIII could be generated by any of the three types of cell that comprise this synapse: motor nerve, muscle fiber, or Schwann cells. To distinguish between these possibilities, immunoelectron microscopy with an antimouse (Kvist et al., 2001) (Fig. 1B) and with anti-human (Fig. $1 C$ ) collagen XIII/NC3 antibodies was performed. Collagen XIII immunoreactivity was observed primarily on the synaptic sarcolemma and the adjacent BM (Fig. $1 B, C$, red circles). In some cases, collagen XIII immunoreactivity was also detected in muscle cytoplasm underlying the NMJ (Fig. $1 B$, arrows). The NC3 domain, against which the antibodies were generated, is highly conserved between the human and mouse. Both antibodies recognize the mouse protein (Hägg et al., 2001; Kvist et al., 2001; Sund et al., 2001a; Latvanlehto et al., 2003; Tuomisto et al., 2008) and resulted in similar staining patterns.

The presence of collagen XIII immunoreactivity on postsynaptic membrane suggested that muscle was the main source of collagen XIII at the synapse. To confirm this and to determine the cellular source of collagen XIII present within the synaptic BM, we generated a reporter mouse line (Col13al $\left.{ }^{\text {LacZ }}\right)$ in which a cDNA encoding E. coli $\beta$-galactosidase ( $\mathrm{LacZ}$ ) was inserted into the Col13a1 locus to replace extracellular sequences, simultaneously destroying the functional furin proprotease cleavage site (Snellman et al., 2000a; Väisänen et al., 2004). Importantly, the Col13a1 ${ }^{\text {LacZ }}$ allele (supplemental Fig. S1 $A-C$, available at www.jneurosci.org as supplemental material) resulted in the expression of a collagen XIII/ $\beta$-galactosidase fusion protein (Fig. $2 A$ ) that could not be proteolytically shed and therefore remained inside or on the plasma membrane of its cells of origin.

Highest collagen XIII expression level was observed in lung tissue (supplemental Fig. S2 $B$, available at www.jneurosci.org as supplemental material) (Fig. 3C), but no $\beta$-galactosidase activity was detected in the lungs of the Col13a1 ${ }^{\text {LacZ }}$ mice, suggesting low expression levels per cell in lung. Altogether, histochemical staining for $\beta$-galactosidase activity was robust enough to reveal specific reaction products in only a few selected tissues from the Col13a1 ${ }^{\text {LacZ }}$ line, including skeletal muscle. The $\beta$-galactosidase staining was dim in heterozygous muscle samples (supplemental Fig. S1D,E,G, available at www.jneurosci.org as supplemental material) and, for that reason, also Col13a $1^{\mathrm{LacZ} / \mathrm{LacZ}}$ samples were used to show the staining, although the homozygous mice had phenotypical changes kindred to knock-out mice described later (data not shown). The whole-mount muscle staining was spot like, forming strings across part or all of the muscle width (Fig. $2 B$ ) (supplemental Fig. S1D, available at www.jneurosci.org as supplemental material), suggesting an NMJ pattern. In the crosssections, $\beta$-galactosidase activity was confined exclusively at the outer edges of some of the muscle fibers (Fig. 2C) (supplemental Fig. $\mathrm{S} 1 E$, available at www.jneurosci.org as supplemental material). Immunolabeling with the anti- $\beta$-galactosidase antibody and BTX confirmed that collagen XIII expression was enriched at synaptic sites (Fig. 2D) (supplemental Fig. S1 F, available at www.jneurosci.org as supplemental material). Moreover, $\beta$-galactosidase immunostaining appeared broader than the labeled AChRs. The $\beta$-galactosidase antibody staining was found at NMJs in both fast-twitch and slowtwitch muscle cells (data not shown). In the nonsynaptic portions of muscle, anti- $\beta$-galactosidase antibody also labeled MTJs (data not shown) but not the sarcolemmal membrane or intramuscular nerve fascicles (Fig. 2E). Combined with immunoelectron microscopy results, these findings suggest a postsynaptic origin of collagen XIII.

To clarify these findings, ultrastructural analysis was performed on $\beta$-galactosidase activity at reporter-labeled NMJs in Col13a1 ${ }^{\text {LacZ }}$ samples. At the ultrastructural level, X-gal reaction products (which represent $\beta$-galactosidase activity) were observed in muscle sarcoplasm underneath the NMJ (Fig. $2 F$, left, arrows) (supplemental Fig. S1G, arrows, available at www. jneurosci.org as supplemental material) and at postsynaptic folds (Fig. 2F, right, arrows), indicating subsynaptic expression and 
A
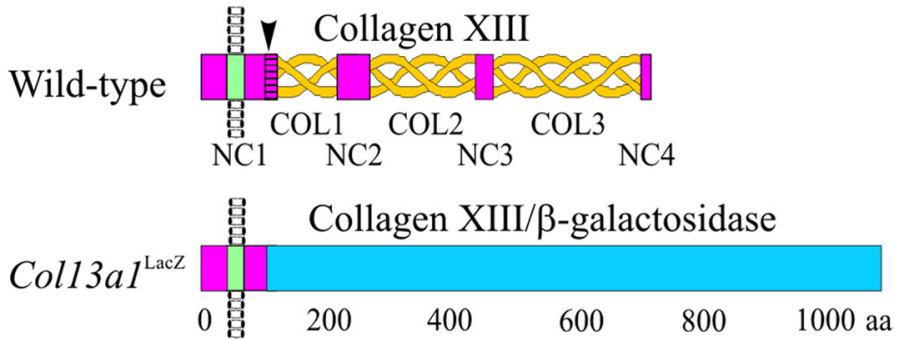

B

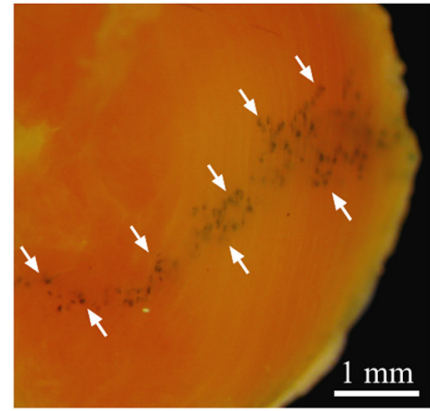

$\beta$-galactosidase activity

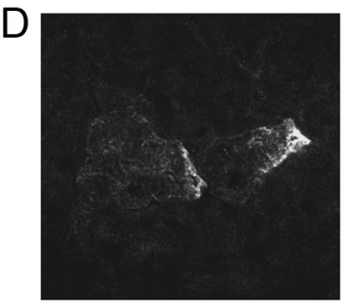

$\beta$-gal

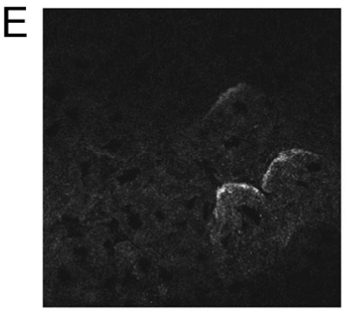

$\beta$-gal

$\mathrm{F}$

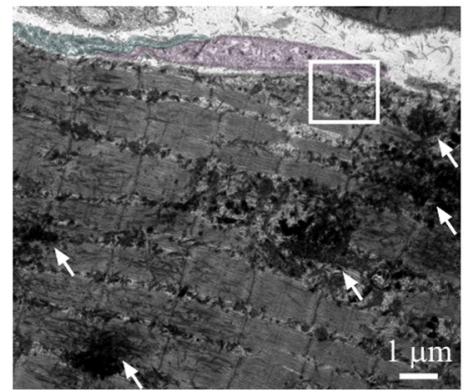

$\beta$-galactosidase activity

G

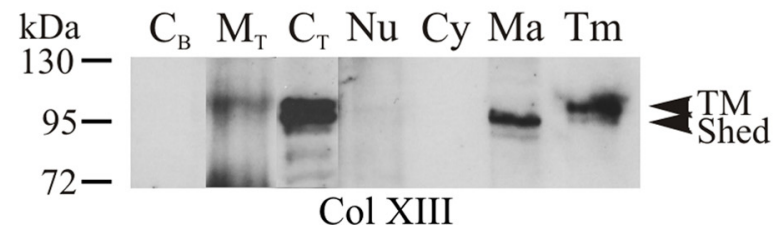

Figure 2. Collagen XIII at the NMJ is expressed by muscle and subjected to shedding. $\boldsymbol{A}$, Schematic presentation of the primary structure of mouse collagen XIII, with collagenous domains (COL1-COL3) indicated by yellow triple helices, non-collagenous synaptic localization for the transmembrane collagen XIII. Expression products were absent from the other cellular components of the NMJ. Thus, these studies demonstrate that membrane- and BMbound collagen XIII are generated by muscle fibers. Consistent with the muscle localization, E-box and N-box sequences, known to enable muscle-specific and NMJ-specific transcription (Gilmour et al., 1991; Koike et al., 1995; Duclert et al., 1996), respectively, were found in human, rat, and mouse collagen XIII genes (supplemental Fig. S2A, available at www. jneurosci.org as supplemental material).

In addition to determining its cellular origin, we used Col13a $1^{\mathrm{LacZ}}$ reporter mice to assess the temporal regulation of collagen XIII expression at the NMJ. $\beta$-Galactosidase reporter expression was weak at NMJs in newborn mice and was only detectable with antibody labeling and not with X-gal histochemistry (data not shown). Reporter activity dramatically increased after the first few postnatal weeks and remained strong at synaptic sites to senescence when using X-gal histochemistry. We confirmed these results with mRNAs isolated from wild-type mus-

\section{$\leftarrow$}

domains (NC1-NC4) in pink, and the membrane-spanning region by a green box. Below is the fusion protein expressed in the Col13a1 ${ }^{\text {Lacz }}$ reporter mice, the blue box indicating $\beta$-galactosidase. Residues encoded by exon 2 are indicated by a pink striped box. Size is indicated in residues (amino acids) and the furin cleavage site by an arrowhead, this being absent from the fusion protein. $\boldsymbol{B}$, Quadriceps muscles from Col13a1 ${ }^{\text {LacZ/LacZ }}$ mice are stained as whole mounts for $\beta$-galactosidase enzyme activity (arrows). C, Cross-sections of whole-mount stained muscles are poststained with eosin. $\boldsymbol{D}$ $\boldsymbol{E}$, Muscle sections from Col13a $1^{\mathrm{LaCZ} /+}$ mice are costained with BTX (green, $\boldsymbol{D}$ ) or anti-neurofilament antibody (NF; green, $\boldsymbol{E}$ ) together with anti- $\beta$-galactosidase antibody ( $\beta$-gal; red). $\boldsymbol{F}$, Muscle whole mounts are stained for $\beta$-galactosidase enzyme activity and studied by electron microscopy, showing crystals (arrows) in the Col13a1 ${ }^{\text {LacZ/LacZ }}$ samples (nerve terminal, transparent purple; Schwann cell, transparent blue). G, Both transmembrane (TM) and shed forms of collagen XIII are detected in Western blotting with the anti-human collagen XIII/ NC3 antibody in the conditioned medium $\left(\mathrm{M}_{\mathrm{T}}\right)$ and cell lysate from differentiated $\mathrm{C} 2 \mathrm{C} 12$ myotubes $\left(\mathrm{C}_{\mathrm{T}}\right)$ but not from $\mathrm{C} 2 \mathrm{C} 12$ myoblasts $\left(C_{B}\right)$. Proteins from differentiated myotubes are fractioned and subjected to Western blotting (Nu, nuclear proteins; Cy, cytoplasmic proteins; Ma, membrane-associated proteins; Tm, transmembrane proteins). Proteins representing $4 \%$ of the proteins in whole-cell lysates, conditioned medium, or in each fraction on a $75 \mathrm{~cm}^{2}$ plate are run per line. In the membrane-associated and membrane fractions, the collagen XIII protein is present as one major and one minor band, which are likely to represent a major and a minor splice form of the collagen XIII transcripts, as reported previously for a number of other tissues (Peltonen et al., 1997). A large amount of serum proteins in the medium sample $\left(M_{T}\right)$ may affect the mobility of the collagen XIII protein on SDS-PAGE, resulting in a higher molecular weight than expected. 
A

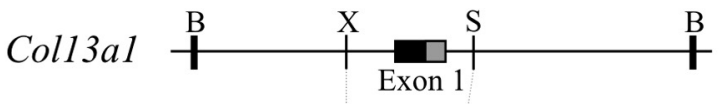

Col13a1

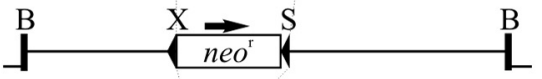

Coll3a1

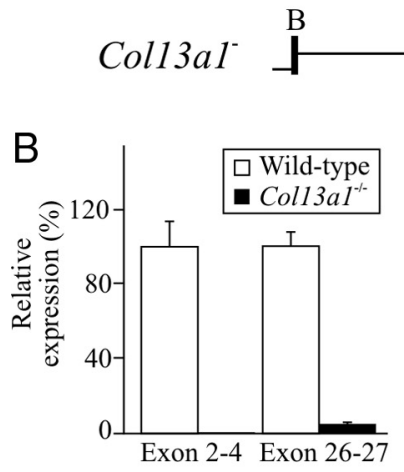

F

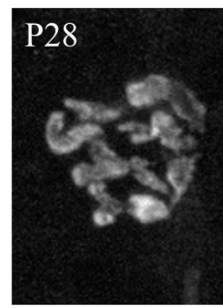

C
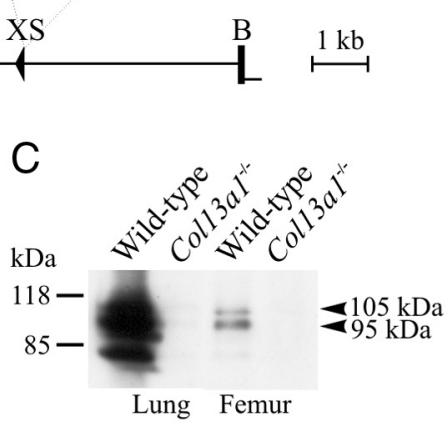

D

Wild-type

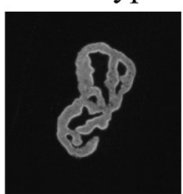

Pretzel

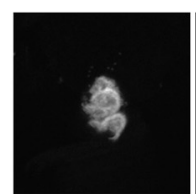

Plaque

Coll $3 a 1$

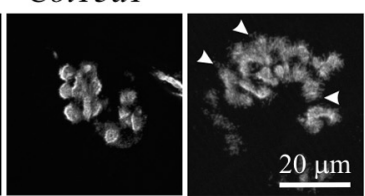

Fragmented Protrusions
Wild-type

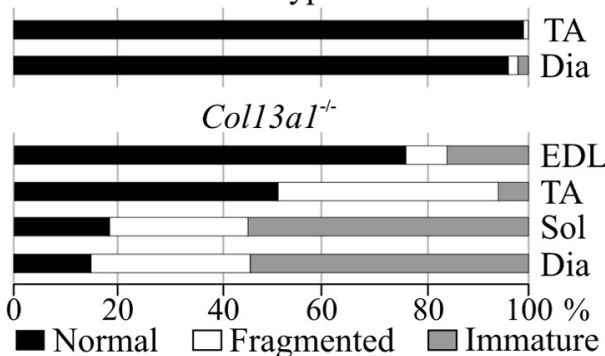

\section{E}

Normal $\square$ Fragmented $\square$ Immature
G

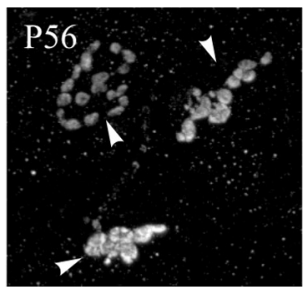

Syt2

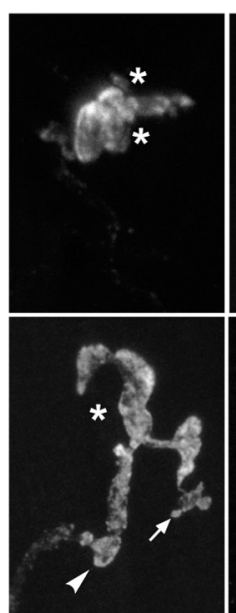

Syt2
Wild-type

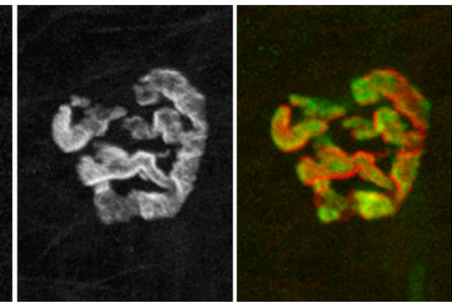

Coll $3 a 1^{-1}$

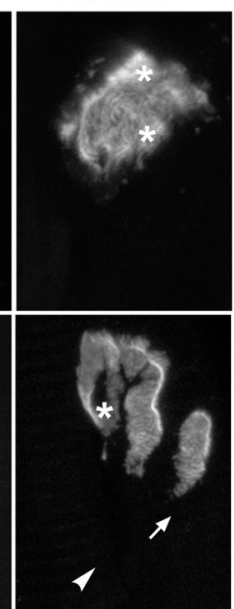

BTX

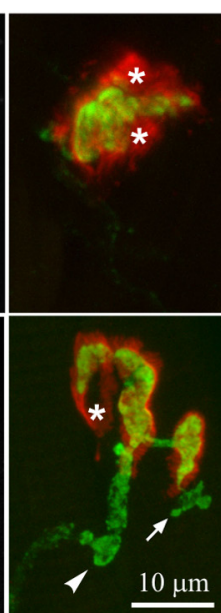

Syt2 / BTX

Col13a1 $1^{-1-}$

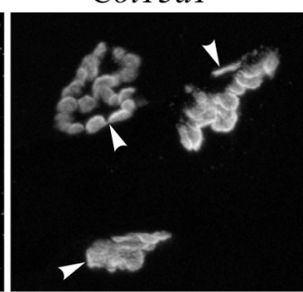

BTX

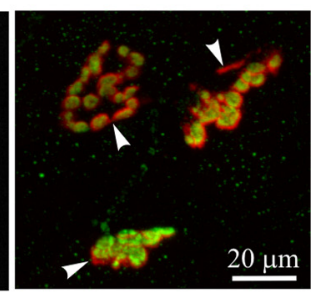

Syt2 / BTX

Figure 3. Collagen XIII is required for presynaptic differentiation. $A$, Restriction of Col13a 1 in the exon 1 area, with $5^{\prime}$ UTR (black) and translated sequences (gray), and generation of a targeted $\left(\mathrm{Col}_{\left.13 a 1^{\top}\right)}\right.$ ) and a knock-out allele (Col13a1 ${ }^{-}$). The loxP sites flanking the PGK-neo ${ }^{r}$, the direction of which is indicated by an arrow, are shown by arrowheads (B, BamHl; $\left.\mathrm{S}, \mathrm{Sfil} ; \mathrm{X}, \mathrm{Xbal}\right) . \boldsymbol{B}$, Quantification of collagen XIII transcripts in wild-type (white columns; $n=4$ ) and Col13a1 ${ }^{-/-}$(black columns; $n=5$ ) E16 fetuses by quantitative real-time $P C R$ with two distinct primer pairs and probes chosen from the areas of exons $2-4$ and exons $26-27$. The value for the wild-type fetuses is defined as $100 \%$ in artificial units as a mean \pm SEM. C, Western blotting of lung and femoral tissues (20 $\mu \mathrm{g} /$ /ine) from wild-type and Col13a1 ${ }^{-1-}$ mice with the anti-human collagen XIII/NC3 antibody. D, Selected high-magnification images of wild-type and Col13a $1^{-1-}$ diaphragms at P56 labeled with BTX (arrowheads; extrajunctional protrusions). $\boldsymbol{E}$, Selected additional muscles at P56 are labeled with BTX, and the AChR clusters are evaluated morphologically (TA, anterior tibialis, $n=$ 92 for wild-type and 91 for Col13a1 ${ }^{-/-}$; Dia, diaphragm, $n=100$ for wild-type and 600 for Col13a1 ${ }^{-/-}$, EDL, extensor digitorum longus, $n=105 ;$ Sol, soleus, $\left.n=138\right)$. F, NMJs in P28 mouse diaphragms are colabeled with anti-Syt2 antibody (green) together with BTX (red). Axonal branches growing beyond AChR clusters are indicated as arrows, and synaptotagmin 2 staining in preterminal axons as arrowheads. G, NMJs in a P56 Col13a ${ }^{-1-}$ mouse diaphragm are colabeled with an anti-Syt2 antibody (green) together with BTX (red; arrowheads, lack of synaptotagmin 2 staining at AChR-positive areas).

cle: quantitative real-time PCR demonstrated little change in the level of Col13a1 mRNA expression between the maturing (1 month) or adult (16 months) muscle, contrary to some other tissues studied (supplemental Fig. S2 B, available at www.jneurosci.org as supplemental material). To assess developmental changes in collagen XIII proteins, proteins were isolated from an immortalized mouse muscle cell line, the $\mathrm{C} 2 \mathrm{C} 12$ cells. In undifferentiated $\mathrm{C} 2 \mathrm{C} 12$ myoblasts, collagen XIII was not detectable. However, after myoblasts fused into myotubes and began to form aneural spontaneous AChR clusters (Kummer et al., 2004), collagen XIII was detected in its major $110 \mathrm{kDa}$ membrane-anchored form and as a $100 \mathrm{kDa}$ shed form (Fig. 2G). The transmembrane form was found in membrane fractions, whereas the shed ectodomain of collagen XIII was enriched in membrane-associated fractions of $\mathrm{C} 2 \mathrm{C} 12$ extracts but was absent from nuclear, cytoplasmic, or membrane fractions (Fig. 2G). Together, these analyses demonstrate that collagen XIII expression is upregulated in muscle after synapses form and mature, and it persists at the synapse throughout the life of the animal. Furthermore, it is likely that the portion of the collagen XIII proteins expressed in vivo by muscle and initially associated with the postsynaptic membrane is shed and relocalized in the synaptic cleft.

Aberrant NMJ morphology in the absence of collagen XIII To evaluate the necessity of collagen XIII at the mouse NMJ, a collagen XIII-deficient mouse line was generated. The predicted promoter, the 5' UTR, and the first protein-coding exon from the 
Col13a1 gene were all deleted to ensure that no truncated forms of collagen XIII could be expressed in mutant mice (Fig. $3 A$ ) (supplemental Fig. S3A-E, available at www.jneurosci.org as supplemental material). Few or no collagen XIII transcripts were detectable in Coll3a1 ${ }^{-/-}$ mice by quantitative real-time PCR (Fig. $3 B$ ), and no protein was detectable in Col13a1 ${ }^{-/-}$tissues by Western blotting (Fig. $3 C$ ) or immunostaining (supplemental Fig. S3F, available at www. jneurosci.org as supplemental material). Therefore, we conclude that Col13a1 ${ }^{-}$is a null allele.

The Coll3a1 ${ }^{-/-}$mice were born in a Mendelian ratio, were fertile, and appeared outwardly normal. The homozygous mutants grew more slowly than their littermate controls at puberty, although their weight was normal at birth and in adulthood (data not shown). Although collagen XIII-deficient mice lived normally into adulthood, they exhibited tremors and worsened general condition in senescence.

To assess synaptic organization, we first examined NMJs in 2-month-old Col13a1 ${ }^{-1-}$ mice and littermate controls by labeling postsynaptic structures with BTX. In control animals, AChR clusters appeared as complex, branched, pretzellike morphologies. The topology of AChR clusters within the postsynaptic membrane of Col13a1 ${ }^{-/-}$mice were abnormal in several ways, being small, simple, plaque like, and/or fragmented (Fig. 3D). In addition, some mutant AChR clusters had thin protrusions into the surroundings (Fig. 3D, arrowheads). The defects reported here were observed in a large proportion of NMJs in mutant diaphragms (supplemental Fig. S4, available at www.jneurosci.org as supplemental material).

In some genetically modified mice, synaptic defects have been reported in some muscles but not in others (Stedman et al., 1991; Dupont-Versteegden and McCarter, 1992). To ascertain whether the defects observed in the Col13a1 ${ }^{-/-}$ diaphragm were unique to that muscle, we examined synaptic architecture of collagen XIII-deficient mice in three additional muscles: the tibialis anterior, extensor digitorum longus, and soleus. The phenotype was qualitatively similar in all four muscles but varied in severity between them (Fig. 3E).

In addition to surveying postsynaptic topology, we assessed nerve terminal morphology in collagen XIII-deficient mutants. This was examined by immunolabeling with antibodies directed against Syt2, a synaptic vesicle-associated protein in motor nerve

A

B

C
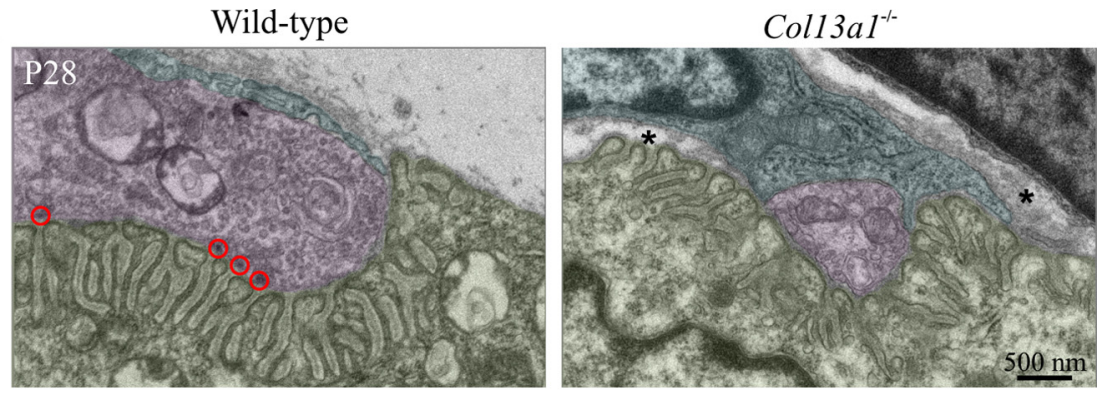

Wild-type
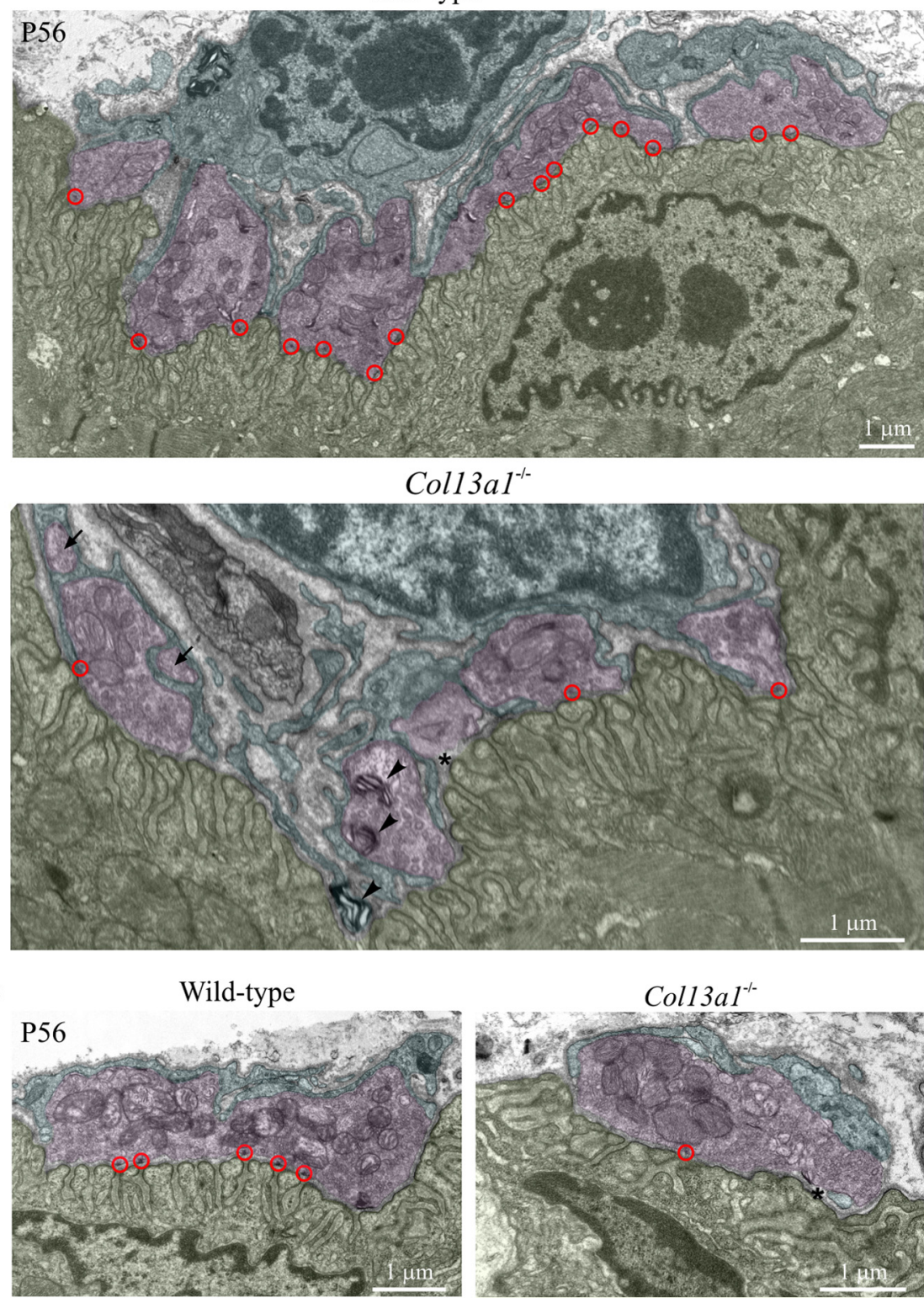

Figure 4. Collagen XIII is required for the adhesion of presynaptic and postsynaptic partners. $A-C$, Electron microscopy of NMJs in the wild-type and Col13a1 ${ }^{-/-}$mouse quadriceps muscle at P28 (A) and diaphragm muscle at P56 (B-C) (muscle, transparent green; nerve terminal, transparent purple; Schwann cell, transparent blue; arrow, enwrapped nerve terminus; arrowhead, degeneration; red circle, active zone). Note the difference in scale bars between wild-type and $\mathrm{Col}_{13 a 1^{-/-}}$samples in $\boldsymbol{B}$ and $\boldsymbol{C}$.

terminals (Fox and Sanes, 2007). In controls, Syt2 immunoreactivity of nerve terminals precisely matched and apposed postsynaptic AChR clusters (Fig. 3F). In mutants, three different presynaptic defects were observed at some synaptic sites; synaptic vesicles failed to properly cluster in nerve terminals and remained 
A

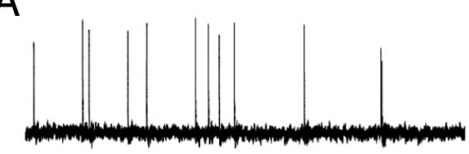

Wild-type

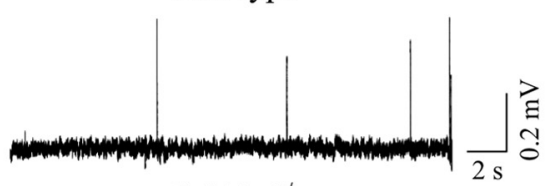

Coll 3 a1 $^{-1-}$

D

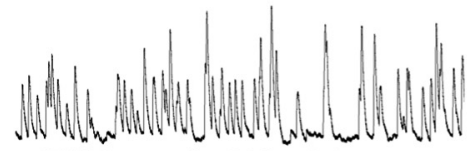

Wild-type in $500 \mathrm{mM}$ sucrose

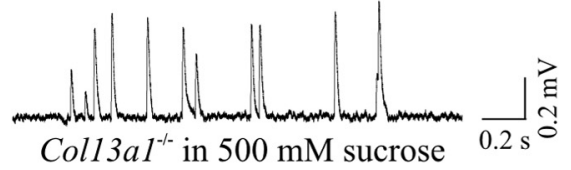

$\mathrm{G}$

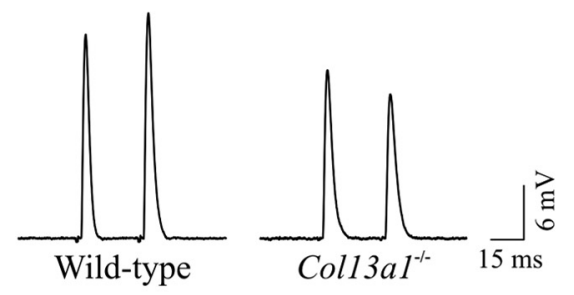

$J$
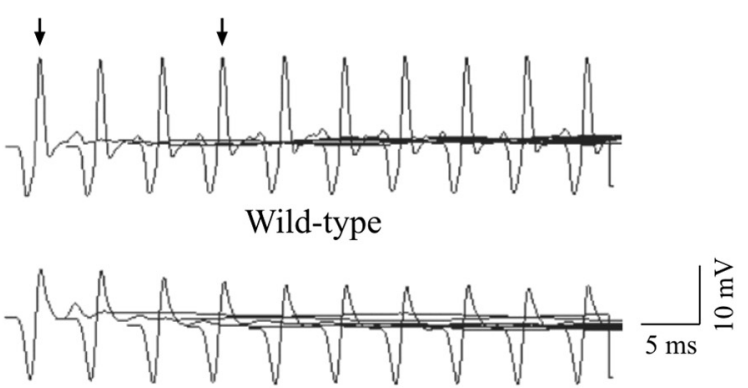

Coll $3 a 1$
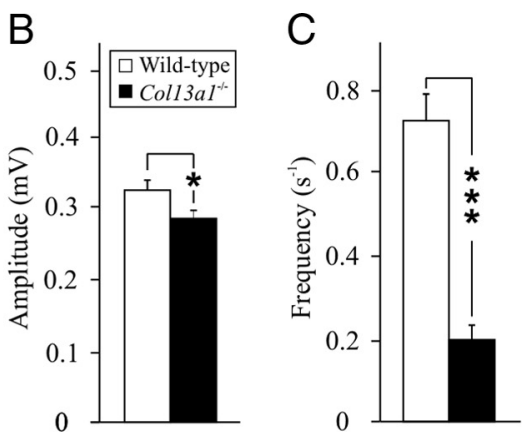

E

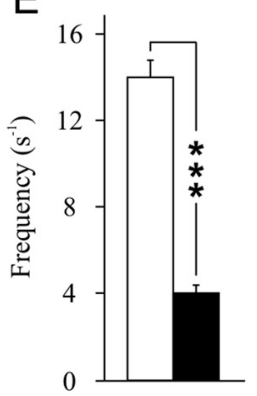

$\mathrm{F}$

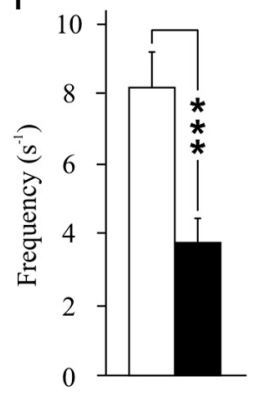

$\mathrm{H}$

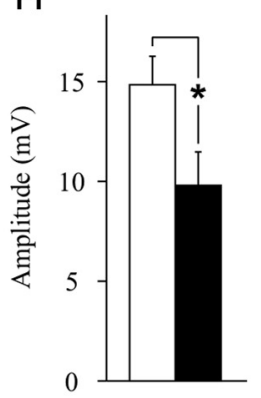

I

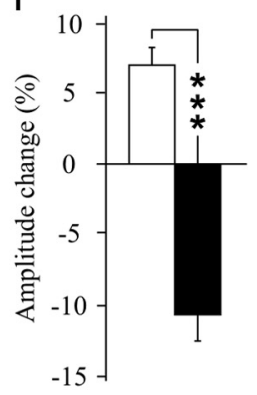

in axons (Fig. 3F, arrowheads), nerve terminals failed to fully cover AChR clusters (Fig. 3F, asterisks), and synaptic vesiclerich sprouts extended beyond the borders of postsynaptic specializations (Fig. 3F, arrows). As opposed to the widespread defects in postsynaptic topography in collagen XIII-deficient mutants, major presynaptic defects were present only at some synaptic sites, and mild defects in alignment were seen more broadly (Fig. $3 G$ ).

\section{Collagen XIII-deficient NMJs exhibit} marked ultrastructural defects

Defects in collagen XIII-deficient NMJs were further analyzed at the ultrastructural level by electron microscopy at P28 and P56. In control NMJs, nerve terminals precisely apposed postsynaptic membranes and secondary synaptic folds in the muscle membrane (Fig. $4 A-C$ ); additionally, regions of nerve terminals not in contact with muscle fibers were fully capped by the processes of non-myelinating, terminal Schwann cells (Fig. 4A-C). In contrast, many examples of postsynaptic membranes not apposed by nerve terminals were observed in Coll3a1 ${ }^{-/-}$mice at both time points studied. Unapposed postsynaptic sites were in some cases found to be "naked" (Fig. $4 A-C$, asterisks) and in others covered by Schwann cell processes (Fig. 4A-C, see blue pseudo-colored Schwann cells). Schwann cell processes were observed invaginating into the synaptic cleft and/or erroneously wrapping nerve terminals (Fig. $4 B$, arrows). As a result, the contact of presynaptic and postsynaptic counterparts was discontinuous, and the contact surface between muscle and nerve terminal was reduced (Fig. $4 A-C$ ). Furthermore, presynaptic cells showed degenerative changes (Fig. $4 B$, arrowheads). Moreover, fewer presynaptic, clearly definable active zones were found in Col13a1 ${ }^{-/-}$terminals compared with controls (Fig. $4 A-C$, red circles).

Figure 5. Electrophysiological measurements indicate compromised function of the neuromuscular synapse in the lack of collagen XIII. $A, B$, Recording of MEPPs in diaphragm muscle in 3-month-old control and Col13a1 ${ }^{-1-}$ mice indicates amplitudes of $0.33 \pm 0.02 \mathrm{mV}$ in control $\left(n=21\right.$ synapses) versus $0.28 \pm 0.02 \mathrm{mV}$ in Col13a1 ${ }^{-1-}(n=20 ; p=0.04)$. Wild-type samples are indicated by white columns and $C_{0} / 13 a 1^{-1-}$ samples as black columns $(\boldsymbol{B}, \boldsymbol{C} ; \boldsymbol{E}, \boldsymbol{F} ; \boldsymbol{H}, \boldsymbol{I})$. $\boldsymbol{C}$, The frequency of MEPPs is $0.73 \pm 0.06$ for wild-type $(n=21)$ and $0.20 \pm 0.04 \mathrm{~s}^{-1}$ for Col13a1 ${ }^{-1-}(n=20 ; p<0.001)$ mice. $\boldsymbol{D}, \boldsymbol{E}$, Sucrose at $500 \mathrm{~mm}$ increases the frequency of ACh release to $13.97 \pm 0.82$ in wild-type $(n=31)$ compared with $3.99 \pm 0.37 \mathrm{~s}^{-1}$ in Col13a1 ${ }^{-/-}(n=32 ; p<0.001)$ samples. $\boldsymbol{F}$, Potassium at $15 \mathrm{~mm}$ increases the frequency of ACh release to $8.10 \pm 0.94$ in wild-type $(n=26)$ and $3.79 \pm 0.61$ in Col13a1 ${ }^{-1-}(n=37 ; p<0.001)$ mice. $\boldsymbol{G}, \boldsymbol{H}$, The

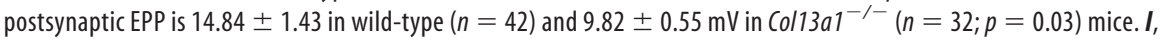
Paired-pulse stimulation with the interstimulus interval of $30 \mathrm{~ms}$ induces increase in amplitude to $7.10 \pm 1.26$ in wild-type mice $(n=42)$, although it leads to depression of $-10.47 \pm 1.88 \%$ in Col13a $1^{-/-}$mice $(n=32$; showing $p<0.001$ with Mann-Whitney test). $\boldsymbol{J}, \boldsymbol{K}$, The sciatic nerve of 3-month-old wild-type $(n=13)$ and $\mathrm{Col13a1}^{-/-}(n=12)$ male mice is repetitively stimulated at $3 \mathrm{~Hz}$ in electroneuromyography. Maximum decrement (percentage) of the amplitude is determined between the second and fifth compound muscle potential after stimulation (arrows in $J$ ). Means (wild-type, 1.6; Col13a1 $\left.{ }^{-/-},-0.3\right)$ are indicated by striated lines $(\boldsymbol{K})$.

\section{Compromised function of the} neuromuscular synapse in the absence of collagen XIII

To determine whether the morphological abnormalities observed in collagen XIIIdeficient mutants resulted in defective neural function, electrophysiological recordings were performed in vitro. The resting membrane potential in diaphragm muscle was unaltered in Coll3a1 ${ }^{-/-}$mice when compared with controls $(75.55 \pm$ 0.55 for controls calculated as mean \pm SEM, $n=55$ synapses; $77.74 \pm 0.95 \mathrm{mV}$, $n=39$ for Coll3a1 ${ }^{-/-}$mice; $p>0.05$ with Student's $t$ test). Although the amplitude 
of MEPPs (Fig. 5A) in Col13a1 ${ }^{-1-}$ mice were slightly, but significantly, reduced (Fig. 5B), the frequency of MEPPs was dramatically reduced in mutants compared with controls (Fig. 5C), indicating a low probability of spontaneous quantal release of ACh in mice lacking collagen XIII. The rise time and decay time of MEPPs were unchanged, suggesting that receptor kinetics was unchanged (data not shown).

Evaluation of the readily releasable pool (RRP) in hypertonic solution also indicated impaired presynaptic function because the sucrose-induced enhancement of ACh quantal release (Fig. 5D) was considerably compromised in Col13a1 $1^{-/-}$mice when compared with controls (Fig. 5E). In line with this, high concentration of potassium induced much less efficient increase in ACh secretion in Col13a1 ${ }^{-/-}$mice than in controls (Fig. 5F), again implying insufficient electrosecretion coupling. The stimulation of motor nerve elicited postsynaptic EPPs (Fig. 5G), which were slightly reduced in Col13a1 ${ }^{-/-}$mice (Fig. 5H). However, paired-pulse stimulation induced facilitation in control, whereas the same pattern of stimulation indicated paired-pulse depression in Col13a1 ${ }^{-/-}$mice (Fig. 5I), consistent with reduced readily releasable transmitter pool. Altogether, electrophysiological recordings indicated dominating presynaptic dysfunction in mice lacking collagen XIII.

For the evaluation of peripheral nerve function and neuromuscular transmission, NCV and repetitive stimulation studies were performed. None of the parameters indicating motor or sensory nerve function was altered in 3-month-old mice lacking collagen XIII when compared with controls (supplemental Table S1, available at www.jneurosci.org as supplemental material). We saw a slight decrement in the calculated average of response to repetitive stimulation in the Col13a1 ${ }^{-/-}$study group when compared with controls, although the postsynaptic function was considerably compromised in only one mutant mouse (Fig. $5 \mathrm{~J}, \mathrm{~K}$ ). Additionally, Col13a1 ${ }^{\mathrm{N} / \mathrm{N}}$ mice harboring only the shed form of collagen XIII (Kvist et al., 2001) did not show any defects in the EMG experiment, whereas approximately half of the Col13a1 $1^{\text {LacZ/LacZ }}$ mice exhibited clear decrement in the response to repetitive stimulus (data not shown). Thus, the $\beta$-galactosidase enzyme replacing the collagen XIII ectodomain contributes to more severe symptoms when compared with simple collagen XIII deficiency.

\section{Collagen XIII acts on muscle to induce postsynaptic maturation}

Presynaptic and postsynaptic elements are dependent on transsynaptic signals in such a manner that defects on one side of the synapse are likely to induce changes in the apposing synaptic partners. Therefore, the morphological and functional defects described above could arise from collagen XIII affecting directly the presynaptic membrane, the postsynaptic membrane, or both. To determine whether collagen XIII had direct effects on muscle, we used a previously established in vitro assay for postsynaptic differentiation (Kummer et al., 2004), and, indeed, the collagen
XIII ectodomain had direct effects on cultured C2C12 myotubes. In control C2C12 myotube cultures, aneural AChR clusters form in the presence of laminin (Kummer et al., 2004). With time, these initially plaque and ring-like AChR clusters morphologically differentiate to resemble complex, pretzel-like AChR clusters found in vivo and finally disperse. The addition of the collagen XIII ectodomain (but not other collagenous molecules such as collagen IV) (data not shown; but see Fox et al., 2007) had no effect on the number of AChR clusters formed but greatly accelerated their development from plaque-like to pretzel-like structures and fastened their final dispersion into fragments. The effect of collagen XIII was apparent at $3 \mathrm{~d}$ post-myoblast fusion (DPF) (Fig. 6A) but was more striking by 4 DPF (Fig. 6B). With increasing concentration, collagen XIII ectodomaintreated AChR clusters eventually dispersed, a phenomenon observed in control cultures if maintained for $7 \mathrm{DPF}$. Therefore, collagen XIII could be actively signaling in AChR maturation or could be merely enhancing their eventual dispersion. To distinguish between these possibilities, we examined the presence of LL5 $\beta$, an intracellular component of maturing AChR clusters (Kishi et al., 2005), in collagen XIII-treated cultures. Accumulation of LL5 $\beta$ was observed at and within the borders of collagen XIII-induced AChR clusters, suggesting that soluble collagen XIII ectodomain was affecting the maturation of receptor clusters rather than their direct dispersion (Fig. 6C) (for an additional description of the staining pattern, see Kishi et al., 2005; Proszynski et al., 2009).

To assess whether collagen XIII was required for postnatal maturation of postsynaptic sites in vivo, AChR clusters were labeled in developing control and Col13a1 ${ }^{-/-}$mice. At early perinatal ages ( $\mathrm{P} 0-\mathrm{P} 10)$, the number, size, and shape of AChR clusters were indistinguishable between control and mutant NMJs. At 2 weeks of age (P14), subtle defects in mutant AChR clusters were observed: whereas control AChR plaques had begun 

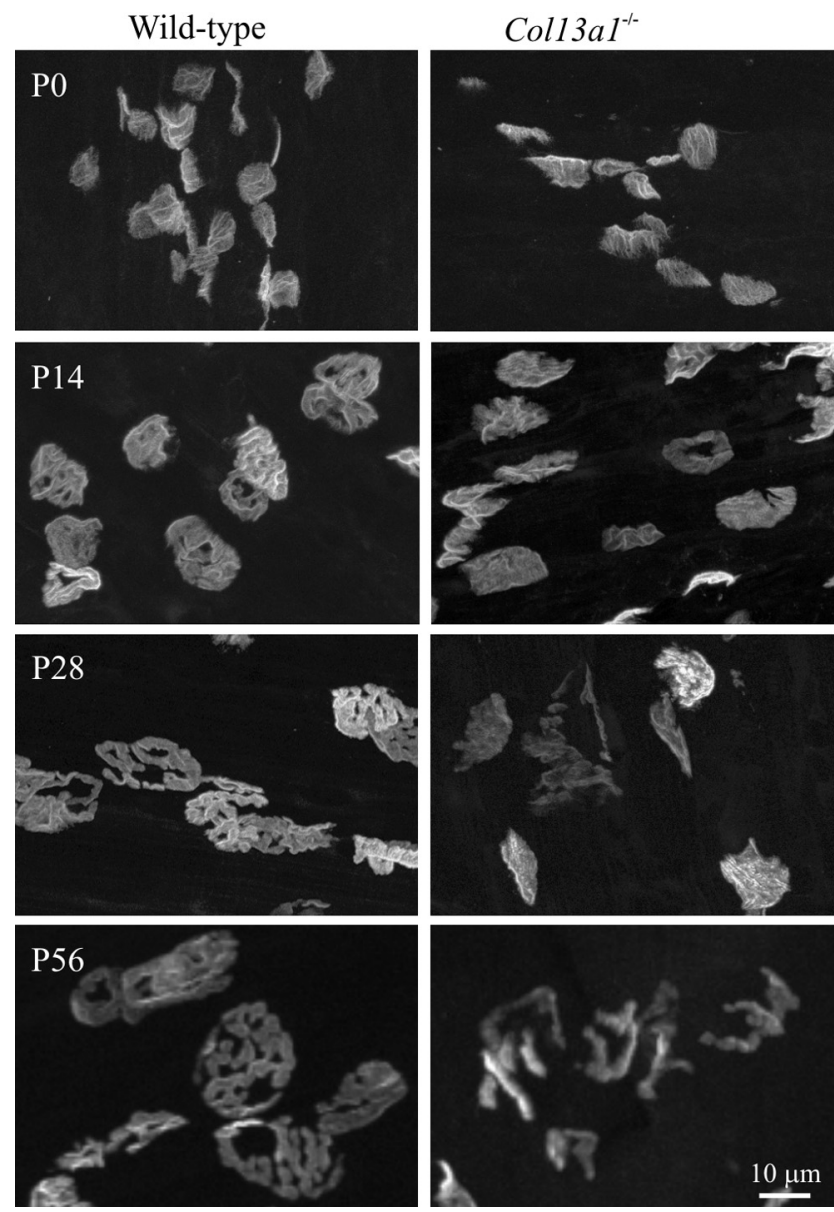

Figure 7. Collagen XIII has a role in postsynaptic maturation. NMJs from wild-type and Col13a1 ${ }^{-1-}$ diaphragms are labeled with BTX at P0, P14, P28, and P56.

to develop branches, mutant AChR clusters remained primarily unperforated and unbranched (Fig. 7). Despite these subtle defects, mutant and control AChR clusters appeared similar in size at P14. By P28, and at P56, Col13a1 ${ }^{-/-}$AChR clusters remained small, simple, and plaque like, whereas NMJs in control muscles appeared dramatically larger and morphologically complex, hallmark features of fully mature NMJs. Mutant AChR clusters never matured to the stage seen in control muscle. Therefore, the premature advancement of AChR clusters in the presence of collagen XIII ectodomain in vitro is in line with the in vivo results demonstrating that collagen XIII is required for AChR cluster maturation. Together, these studies show that collagen XIII is necessary to advance the morphological development of AChR clusters. Together, these in vitro and in vivo data suggest that at least some of the morphological and function defects in collagen XIIIdeficient NMJs arise from direct effects of collagen XIII ectodomain on muscle at the NMJ.

\section{Discussion}

The location of collagen XIII in various cell-matrix and cell-cell junctions is suggestive of adhesive roles, and its occurrence as a transmembrane and shed protein may modulate such functions. Its physiological role has remained unidentified, however. We deduce here, based on the location of a collagen XIII/ $\beta$ galactosidase fusion protein in Col13a $1^{\mathrm{LacZ}}$ mice, that collagen XIII is expressed by subsynaptic nuclei at the skeletal NMJ and that its transmembrane form is concentrated at the postsynaptic membrane. Moreover, collagen XIII was present in both the membrane-spanning and membrane-associated protein fractions of cultured muscle cells. Together, the immunohistochemical, biochemical, and knock-in results show that collagen XIII is expressed by muscle and suggest that some of its ectodomain is shed into the synaptic cleft.

Synapse formation is orchestrated by signals that pass between presynaptic and postsynaptic elements and associated glial cells. Several muscle-derived molecules have been implicated as transsynaptic regulators of presynaptic differentiation and maturation at the skeletal NMJ and also as autocrine regulators of postsynaptic differentiation and maintenance (Noakes et al., 1995; Patton et al., 2001; Fox et al., 2007; Fox, 2008; Nishimune et al., 2008). We present evidence here that collagen XIII affects synaptic maturation. Although collagen XIII appeared dispensable for the formation of the postsynaptic apparatus, immature AChRrich plaques failed to develop into full-sized, complex postsynaptic specializations in the absence of collagen XIII. Moreover, soluble collagen XIII ectodomain was capable of inducing AChR clustering in vitro, suggesting an autocrine role for shed collagen XIII in enhancing AChR clustering. The fact that proteolytically shed collagen XIII remained associated with the membranes of cultured muscle cells supports an autocrine role for collagen XIII at the NMJ. Laminin-521 has also been shown recently to promote postsynaptic maturation in an autocrine manner, by means of an interaction with dystroglycan (Nishimune et al., 2008). Similarities between the postsynaptic defects seen in the absence of collagen XIII and those in laminin and dystroglycan mutants suggest that collagen XIII and the laminins act in conjunction or play related roles at the NMJ.

In addition to delayed postsynaptic maturation, striking defects in presynaptic structure and function were observed in the absence of collagen XIII. It is possible that presynaptic defects are consequences of delayed or faulty postsynaptic maturation. Alternatively, collagen XIII may exert other influences on presynaptic development. One possibility is that nerve terminal defects may reflect critical interactions between collagen XIII and other components of the synaptic BM. It has been shown that the ectodomain of collagen XIII can bind collagen IV with moderate affinity in vitro (Tu et al., 2002). Moreover, it is interesting to note that fibroblasts derived from the Col13a1 ${ }^{\mathrm{N} / \mathrm{N}}$ mouse line lacking the transmembrane form of collagen XIII, but retaining synthesis of the shed form, exhibit decreased adhesion to a collagen IV substratum (Kvist et al., 2001). Shed ectodomain of collagen XIII has been proven capable of remodeling the composition of ECM (Väisänen et al., 2006), and, in addition to collagen IV, again, synaptic laminins could be potential direct interaction partners or downstream effectors because they have been shown to induce clustering of ACh vesicles (Cho et al., 1998), this by directly binding with presynaptic calcium channels (Nishimune et al., 2004). Also, reduced number of active zones at the preterminal membrane in collagen XIII-deficient mice could result from defective function of synaptic laminins (Patton et al., 2001).

Another alternative explanation for nerve terminal defects in the absence of collagen XIII is that transmembrane collagen XIII may directly link presynaptic and postsynaptic membranes at the NMJ. Although many transmembrane adhesion molecules are not large enough to span the relatively wide synaptic cleft at the NMJ, the extracellular domain of collagen XIII is a rod-like structure capable of spanning $150 \mathrm{~nm}$ (Tu et al., 2002) and is therefore easily capable of acting as a transsynaptic adhesion molecule at the NMJ. Candidate receptors for collagen XIII on the presynaptic membrane include integrins, such as $\alpha 1 \beta 1$ integrin. The inte- 
grin $\alpha 1$ subunit is a receptor for collagen XIII in cultured cells (Nykvist et al., 2000) and has been shown to be present on mouse motor nerve terminals (Martin et al., 1996). A role for collagen XIII as a transsynaptic adhesion molecule may explain both the decreased apposition between nerve terminal and postsynaptic membrane and the invasion of Schwann cell processes into the synaptic cleft in the absence of collagen XIII. Similarly to what was observed previously for laminin $\beta 2$ mutants, Schwann cells invade into the synaptic cleft in the collagen XIII mutants, but the Schwann cell contact with the synaptic BM is less tight in the latter mutants. This suggests that collagen XIII does not harbor a direct inhibitory role in Schwann cell binding with the BM, as has been suggested for laminin $\beta 2$ (Patton et al., 1998). It is possible that synaptic laminins and collagen XIII interact directly or indirectly. However, the phenotypes do not occur at the same time in the laminin $\beta 2$ and collagen XIII knock-outs, although both proteins are present at the same times. Moreover, the presynaptic phenotype is far more striking in the laminin $\beta 2$ knock-out model (Noakes et al., 1995; Fox et al., 2007). Thus, it is possible that the two proteins may convey similar kinds of functions independently.

The structural changes coincided with functional defects in the collagen XIII mutants. Although the topology of the postsynaptic portion of the NMJ in collagen XIII mutants was considerably defective, the ultrastructural appearance was nearly normal. In line with this, the function of the postsynaptic membrane was shown to be compromised slightly or moderately when both assessing the in vivo response to repetitive stimulations and using in vitro electrophysiological approaches. However, dramatic reduction in the probability of spontaneous neurotransmitter release was observed along with significant reduction in the size of the RRP of transmitters at the motor nerve terminals. The slightly reduced amplitude of spontaneous events cannot be explained by the low level of the resting membrane potentials, because these were similar in wild-type and collagen XIII-deficient mice. Instead, it is conceivable that this reduction could originate from the reduced contact surface area between presynaptic and postsynaptic membranes detected in ultrastructural studies. In line with the reduced level of ACh release in sucrose and in high potassium, evoked multiquantal synaptic potentials were reduced both during single shock and under paired-pulse stimulation. Altogether, these data predict that the NMJs of such mice should demonstrate either reduced efficacy or diminished safety factor (Wood and Slater, 2001), finally leading to the muscle weakness especially during prolonged activation. Such a dramatic downregulation of spontaneous release along modest changes in single EPPs most probably indicated not only morphological immaturity but also presynaptic intracellular malfunctioning. Thus, not only the presynaptic RRP but also the efficiency of evoked release and the paired-pulse facilitation were primarily reduced in collagen XIII mutants, suggesting more global impairment of releasing machinery and/or quantal mobilization. A possible explanation for the presynaptic malfunctioning in mice lacking the postsynaptic collagen XIII could be that the postsynaptic collagen stabilizes presynaptic action via the transsynaptic extracellular matrix, in analogy with synaptic laminins (Knight et al., 2003). Added to this, shed collagen XIII may also harbor short-term retrograde stimulatory actions on nerve terminus. Functional studies nicely confirm observations at morphological and ultrastructural levels. Moreover, a normal response to repetitive stimulation in the Col13a1 ${ }^{\mathrm{N} / \mathrm{N}}$ mice harboring only a shed form of collagen XIII, but lacking the transmembrane form, supports the suggested autocrine role for the shed protein.
All in all, collagen XIII affects neuromuscular maturation in at least three ways. First, it is required for maturation of the postsynaptic membrane. This effect may be at least partly autocrine in that recombinant collagen XIII promotes postsynaptic maturation in cultured myotubes. Second, it has subtle effects on ACh vesicle accumulation in presynaptic maturation. These effects may reflect indirect modulatory interaction with, for example, synaptic BM components, such as collagen IV or synaptic laminins known to exert direct effects on nerve terminals. Third, collagen XIII participates in transsynaptic adhesion, possibly by binding directly to the nerve terminals and/or terminal Schwann cells and/or functioning in retrograde signaling. Defects in such functions in collagen XIII mutants lead to marked changes at the structural integrity of the NMJ. Reduced contact surface together with lower number of ACh release sites lead to reduced readily releasable transmitter pool. When this collagen is lacking, the structure of the NMJ is severely affected and neurotransmission is compromised. Together, our results demonstrate that collagen XIII is a multifunctional NMJ component and raise the possibility that loss of collagen XIII or the presence of antibodies to it could contribute to myasthenic disorders.

\section{References}

Cho SI, Ko J, Patton BL, Sanes JR, Chiu AY (1998) Motor neurons and Schwann cells distinguish between synaptic and extrasynaptic isoforms of laminin. J Neurobiol 37:339-358.

Duclert A, Savatier N, Schaeffer L, Changeux JP (1996) Identification of an element crucial for the sub-synaptic expression of the acetylcholine receptor epsilon-subunit gene. J Biol Chem 271:17433-17438.

Dupont-Versteegden EE, McCarter RJ (1992) Differential expression of muscular dystrophy in diaphragm versus hindlimb muscles of mdx mice. Muscle Nerve 15:1105-1110.

Fässler R, Meyer M (1995) Consequences of lack of beta 1 integrin gene expression in mice. Genes Dev 9:1896-1908.

Feng G, Krejci E, Molgo J, Cunningham JM, Massoulié J, Sanes JR (1999) Genetic analysis of collagen Q: roles in acetylcholinesterase and butyrylcholinesterase assembly and in synaptic structure and function. J Cell Biol 144:1349-1360.

Fox MA (2008) Novel roles for collagens in wiring the vertebrate nervous system. Curr Opin Cell Biol 20:508-513.

Fox MA, Sanes JR (2007) Synaptotagmin I and II are present in distinct subsets of central synapses. J Comp Neurol 503:280-296.

Fox MA, Umemori H (2006) Seeking long-term relationship: Axon and target communicate to organize synaptic differentiation. J Neurochem 97:1215-1231.

Fox MA, Sanes JR, Borza DB, Eswarakumar VP, Fässler R, Hudson BG, John SW, Ninomiya Y, Pedchenko V, Pfaff SL, Rheault MN, Sado Y, Segal Y, Werle MJ, Umemori H (2007) Distinct target-derived signals organize formation, maturation, and maintenance of motor nerve terminals. Cell 129:179-193.

Gautam M, Noakes PG, Moscoso L, Rupp F, Scheller RH, Merlie JP, Sanes JR (1996) Defective neuromuscular synaptogenesis in agrin-deficient mutant mice. Cell 85:525-535.

Gilmour BP, Fanger GR, Newton C, Evans SM, Gardner PD (1991) Multiple binding sites for myogenic regulatory factors are required for expression of the acetylcholine receptor gamma-subunit gene. J Biol Chem 266: 19871-19874.

Giniatullin RA, Khazipov RN, Vyskocil F (1993) A correlation between quantal content and decay time of endplate currents in frog muscles with intact cholinesterase. J Physiol 466:95-103.

Gossler A, Zachgo J (1993) Gene and enhancer trap screens in ES cell chimeras. In: Gene targeting-A practical approach (Joyner AL, ed), pp 181234. New York: Oxford UP.

Hägg P, Rehn M, Huhtala P, Väisänen T, Tamminen M, Pihlajaniemi T (1998) Type XIII collagen is identified as a plasma membrane protein. J Biol Chem 273:15590-15597.

Hägg P, Väisänen T, Tuomisto A, Rehn M, Tu H, Huhtala P, Eskelinen S, Pihlajaniemi T (2001) Type XIII collagen: a novel cell adhesion compo- 
nent present in a range of cell-matrix adhesions and in the intercalated discs between cardiac muscle cells. Matrix Biol 19:727-742.

Kimura J (2001) Electrodiagnosis in diseases of nerve and muscle: principles and practice. New York: Oxford UP.

Kishi M, Kummer TT, Eglen SJ, Sanes JR (2005) LL5beta: a regulator of postsynaptic differentiation identified in a screen for synaptically enriched transcripts at the neuromuscular junction. J Cell Biol 169:355-366.

Knight D, Tolley LK, Kim DK, Lavidis NA, Noakes PG (2003) Functional analysis of neurotransmission at beta2-laminin deficient terminals. J Physiol 546:789-800.

Koike S, Schaeffer L, Changeux JP (1995) Identification of a DNA element determining synaptic expression of the mouse acetylcholine receptor delta-subunit gene. Proc Natl Acad Sci U S A 92:10624-10628.

Kummer TT, Misgeld T, Lichtman JW, Sanes JR (2004) Nerve-independent formation of a topologically complex postsynaptic apparatus. J Cell Biol 164:1077-1087.

Kummer TT, Misgeld T, Sanes JR (2006) Assembly of the postsynaptic membrane at the neuromuscular junction: paradigm lost. Curr Opin Neurobiol 16:74-82.

Kvist AP, Latvanlehto A, Sund M, Horelli-Kuitunen N, Rehn M, Palotie A, Beier D, Pihlajaniemi T (1999) Complete exon-intron organization and chromosomal location of the gene for mouse type XIII collagen (coll3a1) and comparison with its human homologue. Matrix Biol 18:261-274.

Kvist AP, Latvanlehto A, Sund M, Eklund L, Väisänen T, Hägg P, Sormunen R, Komulainen J, Fässler R, Pihlajaniemi T (2001) Lack of cytosolic and transmembrane domains of type XIII collagen results in progressive myopathy. Am J Pathol 159:1581-1592.

Latvanlehto A, Snellman A, Tu H, Pihlajaniemi T (2003) Type XIII collagen and some other transmembrane collagens contain two separate coiledcoil motifs, which may function as independent oligomerization domains. J Biol Chem 278:37590-37599.

Martin PT, Kaufman SJ, Kramer RH, Sanes JR (1996) Synaptic integrins in developing, adult, and mutant muscle: selective association of alphal, alpha7A, and alpha7B integrins with the neuromuscular junction. Dev Biol 174:125-139.

Nagy A, Rossant J, Nagy R, Abramow-Newerly W, Roder JC (1993) Derivation of completely cell culture-derived mice from early-passage embryonic stem cells. Proc Natl Acad Sci U S A 90:8424-8428.

Nishimune H, Sanes JR, Carlson SS (2004) A synaptic laminin-calcium channel interaction organizes active zones in motor nerve terminals. Nature 432:580-587.

Nishimune H, Valdez G, Jarad G, Moulson CL, Müller U, Miner JH, Sanes JR (2008) Laminins promote postsynaptic maturation by an autocrine mechanism at the neuromuscular junction. J Cell Biol 182:1201-1215

Noakes PG, Gautam M, Mudd J, Sanes JR, Merlie JP (1995) Aberrant differentiation of neuromuscular junctions in mice lacking s-laminin/laminin beta 2. Nature 374:258-262.

Nykvist P, Tu H, Ivaska J, Käpylä J, Pihlajaniemi T, Heino J (2000) Distinct recognition of collagen subtypes by alpha(1)beta(1) and alpha(2)beta(1) integrins. alpha(1)beta(1) mediates cell adhesion to type XIII collagen. J Biol Chem 275:8255-8261.

Ortega N, Werb Z (2002) New functional roles for non-collagenous domains of basement membrane collagens. J Cell Sci 115:4201-4214.

Patton BL, Chiu AY, Sanes JR (1998) Synaptic laminin prevents glial entry into the synaptic cleft. Nature 393:698-701.

Patton BL, Cunningham JM, Thyboll J, Kortesmaa J, Westerblad H, Edström L, Tryggvason K, Sanes JR (2001) Properly formed but improperly localized synaptic specializations in the absence of laminin alpha4. Nat Neurosci 4:597-604.

Peltonen S, Rehn M, Pihlajaniemi T (1997) Alternative splicing of mouse
alpha1(XIII) collagen RNAs results in at least 17 different transcripts, predicting alpha1(XIII) collagen chains with length varying between 651 and 710 amino acid residues. DNA Cell Biol 16:227-234.

Proszynski TJ, Gingras J, Valdez G, Krzewski K, Sanes JR (2009) Podosomes are present in a postsynaptic apparatus and participate in its maturation. Proc Natl Acad Sci U S A 106:18373-18378.

Rotundo RL (2003) Expression and localization of acetylcholinesterase at the neuromuscular junction. J Neurocytol 32:743-766.

Sakai K, Miyazaki J (1997) A transgenic mouse line that retains cre recombinase activity in mature oocytes irrespective of the cre transgene transmission. Biochem Biophys Res Commun 237:318-324.

Sanes JR (2003) The basement membrane/basal lamina of skeletal muscle. J Biol Chem 278:12601-12604.

Snellman A, Tu H, Väisänen T, Kvist AP, Huhtala P, Pihlajaniemi T (2000a) A short sequence in the $\mathrm{N}$-terminal region is required for the trimerization of type XIII collagen and is conserved in other collagenous transmembrane proteins. EMBO J 19:5051-5059.

Snellman A, Keränen MR, Hägg PO, Lamberg A, Hiltunen JK, Kivirikko KI, Pihlajaniemi T (2000b) Type XIII collagen forms homotrimers with three triple helical collagenous domains and its association into disulfidebonded trimers is enhanced by prolyl 4-hydroxylase. J Biol Chem 275:8936-8944.

Stanley EF (1981) Sensory and motor nerve conduction velocities and the latency of the $\mathrm{H}$ reflex during growth of the rat. Exp Neurol 71:497-506.

Stedman HH, Sweeney HL, Shrager JB, Maguire HC, Panettieri RA, Petrof B, Narusawa M, Leferovich JM, Sladky JT, Kelly AM (1991) The mdx mouse diaphragm reproduces the degenerative changes of duchenne muscular dystrophy. Nature 352:536-539.

Sund M, Väisänen T, Kaukinen S, Ilves M, Tu H, Autio-Harmainen H, Rauvala $\mathrm{H}$, Pihlajaniemi T (2001a) Distinct expression of type XIII collagen in neuronal structures and other tissues during mouse development. Matrix Biol 20:215-231.

Sund M, Ylönen R, Tuomisto A, Sormunen R, Tahkola J, Kvist AP, Kontusaari S, Autio-Harmainen H, Pihlajaniemi T (2001b) Abnormal adherence junctions in the heart and reduced angiogenesis in transgenic mice overexpressing mutant type XIII collagen. EMBO J 20:5153-5164.

Tahkola J, Räsänen J, Sund M, Mäkikallio K, Autio-Harmainen H, Pihlajaniemi T (2008) Cardiac dysfunction in transgenic mouse fetuses overexpressing shortened type XIII collagen. Cell Tissue Res 333:61-69.

Tu H, Sasaki T, Snellman A, Göhring W, Pirilä P, Timpl R, Pihlajaniemi T (2002) The type XIII collagen ectodomain is a $150-\mathrm{nm}$ rod and capable of binding to fibronectin, nidogen-2, perlecan, and heparin. J Biol Chem 277:23092-23099.

Tuomisto A, Sund M, Tahkola J, Latvanlehto A, Savolainen ER, AutioHarmainen H, Liakka A, Sormunen R, Vuoristo J, West A, Lahesmaa R, Morse HC 3rd, Pihlajaniemi T (2008) A mutant collagen XIII alters intestinal expression of immune response genes and predisposes transgenic mice to develop B-cell lymphomas. Cancer Res 68:10324-10332.

Väisänen MR, Väisänen T, Pihlajaniemi T (2004) The shed ectodomain of type XIII collagen affects cell behaviour in a matrix-dependent manner. Biochem J 380:685-693.

Väisänen MR, Väisänen T, Tu H, Pirilä P, Sormunen R, Pihlajaniemi T (2006) The shed ectodomain of type XIII collagen associates with the fibrillar fibronectin matrix and may interfere with its assembly in vitro. Biochem J 393:43-50.

Wood SJ, Slater CR (2001) Safety factor at the neuromuscular junction. Prog Neurobiol 64:393-429.

Ylönen R, Kyrönlahti T, Sund M, Ilves M, Lehenkari P, Tuukkanen J, Pihlajaniemi T (2005) Type XIII collagen strongly affects bone formation in transgenic mice. J Bone Miner Res 20:1381-1393. 